\title{
Work-in-Progress: Conflict-Driven Cooperative Learning in Engineering Courses
}

\section{Dr. Neelam Soundarajan, Ohio State University}

Dr. Neelam Soundarajan is an Associate Professor in the Computer Science and Engineering Department at Ohio State University. His interests include software engineering as well as innovative approaches to engineering education.

\section{Mr. Swaroop Joshi, Ohio State University}

Swaroop is a Ph.D. student in Computer Science and Engineering at The Ohio State University. His interests include a range of problems in software engineering as well as the use of technology in the classroom.

\section{Dr. Rajiv Ramnath, Ohio State University}

Dr. Rajiv Ramnath is Director of Practice at the Collaborative for Enterprise Transformation and Innovation (CETI), and an evangelist for AweSim, a consortium that seeks to bring high-performance computing based modelling and simulation to small and medium enterprises in the Midwest, and an Expert at the National Science Foundation ACI Program. He was formerly Vice President and Chief Technology Officer at Concentus Technology Corp., in Columbus, Ohio, and led product-development and government-funded R\&D - notably through the National Information Infrastructure Integration Protocols program funded by Vice President Gore's ATP initiative. He is now engaged in developing industry-facing programs of applied R\&D, classroom and professional education and technology transfer. His expertise ranges from wireless sensor networking and pervasive computing to business-IT alignment, enterprise architecture, software engineering, e-Government, collaborative environments and work-management systems. He teaches software engineering at OSU and is involved in industry-relevant and inter-disciplinary curriculum development initiatives. Dr. Ramnath received his Doctorate and Master's degrees in Computer Science from OSU and his Bachelor's degree in Electrical Engineering from the Indian Institute of Technology. 


\title{
Work-in-Progress: Conflict-Driven Cooperative-Learning in Engineering Courses
}

\begin{abstract}
Conflict and cooperation would seem to be ideas that are diametrically opposed to each other. But, in fact, classic work by Piaget on how children and adults learn shows that when learners engage with peers in critical discussion of ideas concerning which they have different understandings, that contributes very effectively to learners developing deep understanding of the concepts involved. At the same time, getting students in undergraduate engineering courses to engage with other students in thoughtful discussion of important concepts is very challenging. It can be especially difficult to get female students and students from other underrepresented groups to participate effectively in such discussions. In our work, we exploit the affordances of mobile and web technologies to address these challenges. Our approach not only helps address these challenges, it has a number of other important advantages over face-to-face discussions. We present the theoretical underpinnings of the approach, some details of our prototype implementation, preliminary results from the use of the prototype in a junior/senior level class on Software Engineering, and the design for the next version of the tool.
\end{abstract}

\section{Introduction}

It seems a contradiction in terms. How can conflict even coexist with cooperation, let alone be the driver of cooperative learning? Piaget's classic work ${ }^{1}$ on children's learning provides the answer. It shows that cognitive conflict arising from differences between different learners' understanding of important concepts, and the exploration and possible resolution of these differences by having the learners engage in critical discussion with each other, can be a powerful force in driving students' learning and in helping them develop deep understanding. The key question that our work tries to address is, can we develop an approach based on the idea of cognitive conflict driving cooperative learning that will help improve learning in undergraduate engineering courses?

There are three essential challenges that we face in developing such an approach. First, undergraduate students in engineering (and other technical) courses are quite different, with respect to their willingness to participate in involved discussions with their peers, from the children that Piaget's work focused on. While most young children, after perhaps an initial period of reluctance, willingly engage in such discussions, many of our students, unlike perhaps students in the social sciences, do not. This is especially the case with many female students as well as students from underrepresented groups. 
Second, class sizes tend to be larger, forty students or more being common. So it is difficult to arrange students in groups of 3-4 each and have each group engage in deep discussions without groups disrupting each others' discussions. Moreover, class meeting periods are an hour or less and that may be insufficient for these groups to engage in deep discussions.

Third, faculty, even those who buy in, at some level, to the value of cooperative learning ${ }^{1}$, tend to be concerned about devoting class time to such activities since they are concerned about possible serious negative impact on topic coverage. Our work shows how we can exploit the affordances of mobile and web technologies to address these challenges. As we discuss in the paper, our approach not only helps address these challenges, it has a number of other important advantages over in-person cooperative learning.

One widely used approach to address the issue of the potential impact of cooperative learning and other active learning tasks on topic coverage is that of the flipped classroom $^{6,7}$. The generally accepted definition of the flipped classroom is one where "events that have traditionally taken place inside the classroom now take place outside the classroom and vice versa", see, e.g., 6 . The knowledge transfer that the traditional lecture tries to achieve is instead intended to be achieved, typically, via on-line video lectures which the students are responsible for viewing before attending the inperson class meeting. The class meetings are devoted to answering questions (that students may have based on their viewing of the corresponding video lecture(s)) and problem solving activities including, especially, in cooperative learning groups.

A number of authors ${ }^{7,8,9,10}$ who have used the flipped approach in their courses have reported on both the reaction of the students to the approach and, in some cases, the performance of the students in sections of courses that used the flipped approach compared to that of students in regular (nonflipped) sections of the same courses. Although students seem to enjoy the flipped approach, their performance seems about the same as, or in some cases even worse than, that of students in the regular sections. Thus Thomas and Philpot ${ }^{8}$ reporting on the results from their course on mechanics of materials report, there were "no statistically significant differences between the two groups ... based on performance on the common final exam". Gehringer and Peddycord ${ }^{11}$ report on two courses on computer architecture, one taught as a traditional course, the other as a flipped course. Comparing the performance of students in the two courses, they say, "Despite the engagement successes of the flipped model, our hypothesis that students taught in this way would do better on exams was not borne out ... The average score on common questions was 13.6 for the students [in the flipped course] and 15.6 for students [in the traditional course]".

\footnotetext{
${ }^{1}$ It may be important to note here the distinction between collaborative learning on the one hand and cooperative learning on the other (see, e.g., Olivares ${ }^{2}$ ). Cooperative learning is group learning whose main goal is for every member of the group to learn ${ }^{3,4}$. Our focus is on this type of learning. By contrast, the goal of collaborative learning is for the group to work together to solve a problem, complete a project, etc.; ensuring that each individual member of the group learns some particular item of knowledge is secondary. We should also add that not all authors use these definitions of cooperative and collaborative learning with some authors conflating the two and others interchanging the two terms ${ }^{5,2}$. In any case, there seems to be consensus that there are two types of group activities that students may participate in, with one focusing on each student in the group learning the topic in question, the other focusing on the group, as a whole, solving a problem or completing a project. Our focus, as we noted, is on the former.
} 
We believe the main reasons that the flipped approach has not met expectations with regard to improved performance are the first two challenges we mentioned above. The third challenge, that of coverage, is addressed by the combination of the videos that students are required to watch before class meetings and are also available and often used for later review; plus the time that the instructor spends in class answering questions that students have based on their viewing the videos. But the first challenge, concerning undergraduate students in engineering courses being, as a rule, relatively unwilling to engage in deep conceptual discussions with their peers as well as the second one, concerning class size and the length of class meeting times making it difficult for such discussions to take place, make it difficult for students to engage in effective cooperative learning, a key requirement for flipped courses to work. In fact, it was in order to improve the effectiveness of our junior/senior level course on Software Engineering which uses a flipped approach that we started our work on developing an approach that would address these problems. As it turns out, however, the approach is also applicable to non-flipped courses. That is important because flipping a course, in particular creating effective on-line videos that can replace the instructor's lectures, can be a very demanding task and it is possible, even likely, that many courses will never be flipped. Thus the fact that our approach and tools can help students engage in effective cooperative learning means it will be that much more widely applicable.

The key idea underlying what we call conflict-driven cooperative-learning, henceforth abbreviated CDCL, may be summarized as follows. Small groups of students, typically of size four, whose individual understandings of an important concept or practice are mutually inconsistent with each other, should be required to engage in careful discussion of the topic. In doing so, each student should try to thoroughly grasp the other students' approaches even if, indeed especially if, those approaches sharply differ from her own. Each student should, if it seems called for, based on grasping other students' approaches, revise her own approach. The individual students' revised understandings should then be examined and grasped by each student in the group; etc. The students should go through several rounds of this because it is possible, depending on the complexity of the concept or practice being discussed, that as each student's understanding becomes more refined and the other students in the group grasp the first student's revised approach, their own understandings undergo further revision, given that the students' initial understandings are inconsistent with each other. Each student should be evaluated not on the basis of her initial understanding but on her final understanding as well as on how well the student understands the other students' approaches. It is this head-on tackling, by individual students, of conflicting ideas; and discussing, with peers, the merits or lack thereof of the individual ideas, and trying to discard those which seem wrong, refine those that need to be, etc., to arrive at a final understanding -which may well differ from one student to the next- that is the essence of cooperative learning driven by cognitive conflict. While the basic idea of cognitive conflict driving cooperative learning is based on earlier work, our effective use of mobile technologies extends the approach in such a way that it not only addresses the challenges to having undergraduate students in engineering and other technical courses engage in such learning, it offers other advantages as well.

In Sec. 2, we consider the conceptual background underlying our work. In Sections 3 and 4, we discuss the details of the approach, our initial prototype, some student reactions to the prototype, and a refined version based on those reactions. We conclude in Sec. 4 with a brief summary and plans for future work. 


\section{Conceptual Background}

Over many decades, a number of researchers have investigated the importance of interactions among students in order to best enable learning. For our work, as explained in Section 1, the key notion is that of cognitive conflict ${ }^{1,12}$. Although Piaget was concerned mainly with the intellectual growth of children, his ideas are very relevant for adult learners as well, including computing and engineering students. A key point in Piaget's theory was that peer interaction was a potent component of a learner's grasp of new concepts; in particular, cognitive conflict, i.e., disagreements with other learners' conception of the same problem or topic was fundamental since it highlighted alternatives to the learner's own conception. The learner is forced to consider and evaluate these alternatives on equal terms.

It is critical to note that this is quite different from a teacher telling a learner that his or her conception is incorrect because then, given the authority of the teacher, the learner simply accepts this without critical evaluation. We believe that this is a key reason for the poorer than expected performance of flipped courses. Although students in a typical flipped course do engage in discussions, the discussions are in class and, typically, led by the instructor. Thus in cases where a student's understanding conflicts with the explanation provided by the instructor, the student simply accepts the explanation without careful analysis. Even if the instructor does not directly lead the discussion, when there is a fundamental disagreement among the students in a group during an in-class discussion, they are likely to look to the instructor to tell them which one of them is correct. By contrast, when the (cognitive) conflict has to be analyzed and resolved by the peers without assistance from the instructor, the learner is forced to evaluate the alternatives critically and pick one after careful deliberation since, as far as the student knows, she, rather than the peer, may be the one whose explanation is correct! This is the reason why resolving cognitive conflicts with one's peers is such a powerful tool in helping students develop deep understanding of important concepts. Thus the "cognitive-conflict" in CDCL is among peers. As Howe and Tolmie ${ }^{13}$ put it, "conceptual growth depends on equilibration, that is the reconciliation of conflicts between prior and newly experienced conceptions [obtained by engaging deeply with peers]."

Cognitive conflict is also the primary driving force behind the (in-class) peer instruction technique developed by Mazur ${ }^{14}$ in college-level physics courses. In Mazur's approach, first, each student answers a conceptual multiple choice question submitting the answer via a clicker or other similar device; then the students turn to their neighbors and, in groups of 3 or 4, discuss the question; after a few minutes of discussion, each student again answers the same question. During the discussion time, the instructor may walk around the room, listening in on the discussions, but deliberately does not participate.

Mazur reports that the percentage of students who, following discussion with their peers, change their answer from a wrong choice to the correct one far exceeds the percentage who change from the correct choice to a wrong one. However, there are a number of limitations with this approach, mostly related to the fact that it is a classroom technique with the activity being interspersed with regular lectures by the instructor. First, since the multiple-choice question is about the topic being discussed in the lecture, students may not have spent enough time to think about it deeply. Second, 
there is no way to ensure that the students in a given group include ones who picked different possible answers because the grouping is based essentially on where students happen to be seated. Third, some students tend to dominate their groups even if they don't necessarily have the right answers; this may be especially problematic for students from underrepresented groups, especially women, whose opinions may be ignored in such groups. Fourth, the amount of time spent in the discussion is, naturally, limited; hence, students who are not quick to speak and take time to formulate precise and deliberate arguments may not contribute effectively to the discussions. As we will see, our approach avoids all of these problems.

While computers as well as the web and the internet are used extensively in higher education, this use has been mostly limited to such purposes as making video lectures and other resources available to students; for allowing students at distance locations to attend classes via suitable communication links; and for allowing a limited amount of interaction via e-mail etc. among students and between students and instructors. The use of technology for enabling effective interaction between students for cooperative learning has been quite limited. By contrast, there have been a number of investigations of the use of technology in the K-12 setting to enable various types of interaction among children to help improve their learning. Our work seems unique in its use of mobile and web technologies to enable a novel mode of interaction among undergraduate students in computing/engineering courses to promote effective CDCL.

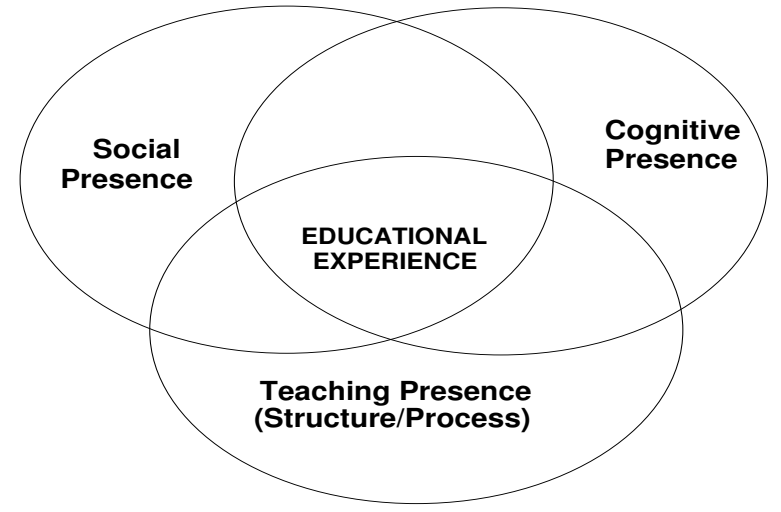

Fig. 1. Community of Inquiry

Fig. 1 depicts the community of inquiry (COI) model for analyzing on-line educational systems. Social presence is the degree to which participants in the learning environment feel affectively connected to each other; cognitive presence represents the extent to which learners are able to, via interactions with each other, construct and refine their understanding of important ideas; teaching presence relates to various instructional activities such as lectures and other activities directed by the teacher. In terms of this model, the focus of our work is to improve the cognitive presence component to promote CDCL. 


\section{The CONSIDER Approach}

For the last several years, we have used a flipped approach in our undergraduate junior/seniorlevel course on software engineering. Lectures are made available as on-line videos which are typically 20 minutes in length. Students are expected to watch the relevant video(s) prior to the class meeting. The class meeting starts with a 15 minute quiz on the topic; below, we consider a typical quiz from the course. Students may post questions about the topic on the class's electronic forum before the class meeting and the instructor or grader answers them. Typically, however, students do not post any questions. Following the quiz, the instructor presents a brief summary of the topic, focusing on the highlights. Then the instructor asks students what choices they made for a particular question on the quiz, picks an individual student, and asks her to explain the choice; other students who may have picked other choices are then asked to explain their choices. The intent is that the resulting discussion will help address any misconceptions that students may have about the topic.

The main purpose of the part of the course related to the quiz below -and this is typically an important part of similar courses elsewhere- is to help students internalize the importance of a systematic approach to understanding the overall domain in which the software system to be built is intended to operate, understand the problem, in the context of the domain, that the software system will help address, and the solution approach to be adopted in the software system. Quite often, students want to jump straight into designing and coding the software system without going through a careful analysis of the domain, the problem in the context of the domain, etc. Indeed, frequently there is confusion between the domain problem and specific algorithmic or data-structure related problems that might be encountered when developing the software. The quiz below is intended to help tease out such misunderstandings.

Quiz 6: Your team has been asked to build a campus wayfinding system to help visually impaired students on campus. Four items identified during analysis are listed below. Identify which category of analysis -that is, domain, problem, or solution- each element falls under. Briefly explain why.

1. A catalog of the various types of building on a campus;

2. The list of hard-to-find buildings on campus;

3. The range of visual and cognitive impairments that people suffer from;

4. Strategies by which people find their way in an unknown area - such as asking passersby or by identifying major streets.

Item (3) is especially interesting. A casual reading might suggest that it belongs under the problem category. But, in fact, it is part of the domain because it provides information about the range of impairments that people suffer from; the software system is not intended to solve the problem of visual impairments (e.g., by developing an artificial eye or something along those lines).

Different students come up with different answers for that item and with different justifications. While the class discussion helps clarify the issues for some students, others remain unclear about 
the distinction between the concepts of domain, problem, and solution. How do we help the students overcome the underlying misconceptions? Based on the idea of CDCL, a good approach would be to divide the class into groups of 4 or 5 students each, each group including students who proposed different answers to the question, and have them discuss the problem and convince each other of the correctness of their individual points of view. But such a discussion cannot take place in class for a number of reasons. First, students in the group need time to mull over the arguments of their peers, especially of those whose opinions they disagree with, in order to convince themselves of the (in)validity of those arguments; and the amount of time needed will vary from student to student since some students understand new ideas, even ones they vehemently disagree with, quickly; others take longer. Second, once they have understood the ideas/arguments of their peer, they need time to dissect it and see whether they agree with it, disagree with it, or even are not sure what to make of it! And, again, the time needed for this step will vary from student to student. Third, once they completed their evaluation, they need time to formulate it in a manner that would be convincing to the other group members, again with the amount of time needed varying from one student to the next.

Moreover, even if we were able to account for all of that, if the discussion were to take place in class, it would be ephemeral and a student would not be able, at a later stage, to reanalyze the arguments and counterarguments of the group. Each student could take detailed notes but that is very unlikely in the heat of the discussion. Finally, there is the problem that some students, especially women and students from some underrepresented groups, tend to find it difficult to effectively present their ideas, especially if there is a dominating personality in the group.

We have designed an approach called CONSIDER -the name being an abbreviation of an approach designed to enable CONflicting Student Ideas to be Discussed, Evaluated, and Resolved (or Refuted!) - to address these problems. The name is also intended to stress the point that each student in a group will be required, as part of the discussion in the group, to seriously consider the ideas of each of the other students in the group. The discussion, as we will see in detail in the next section will be structured in such a way that each student in the group will contribute to the group's discussion and to the discussion and evaluation of the ideas of each of the other student's ideas. And the products generated will, on the one hand, enable the instructor to get a good idea of how well each student has understood the underlying concepts as well as the evolution of that understanding and the contribution made by the other students in the group to that evolution; and, on the other hand, enable each student to carefully review, perhaps in preparation for the final exam in the course, his original understanding of the concept and how his/her engagement in the group and careful consideration of the other students' ideas helped refine/change that understanding. As we will see in the next section, these advantages may be attributed to a large extent to our effective use of the affordances of on-line and mobile technologies. 


\section{The CONSIDER System, Prototype}

The key aspects of the CONSIDER system may be summarized as follows. In preparing for a class meeting, each student is required to individually watch the corresponding video lecture(s). The student will then be required to log into the CONSIDER system where she will be presented with the quiz related to the topic. The quizzes will be similar to the example above but, for now, let us assume there is only one question, in particular, item (3) from the example. The student will be required to make a specific choice (such as "domain" or "problem" or "solution") and, in addition, will be required to include a brief explanation of her choice.

The figure shows the login screen and the next screen of the current prototype of the CONSIDER system, implemented as an Android app. Once the student has successfully logged in, the system displays the quiz, Fig. 1(b). The student does not need to submit the answer to the quiz immediately and may log out/close the app if she would prefer to think the question over before submitting her answer; or she may submit her answer and launch the app again and submit a new answer which will overwrite the answer she

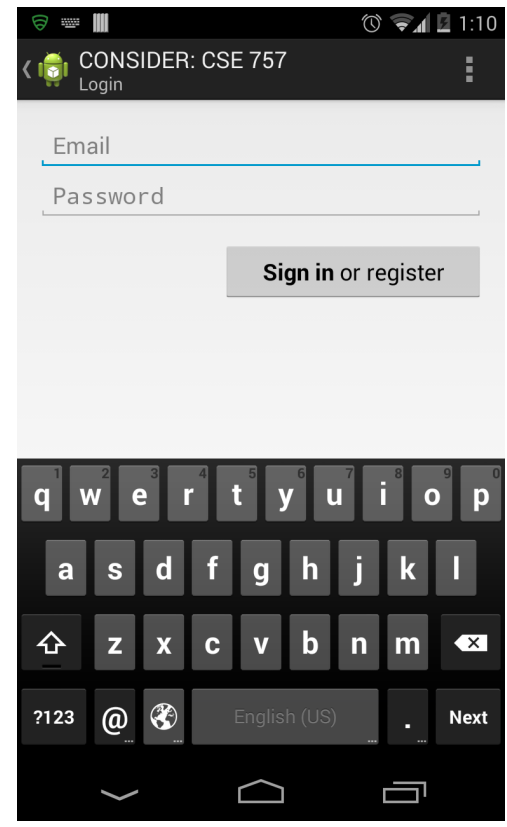

(a) Login

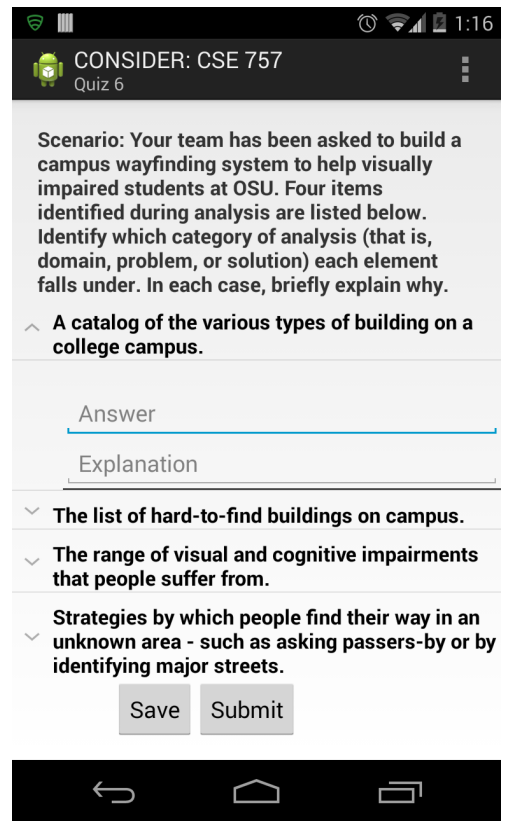

(b) Quiz

Figure 1: Starting Screens submitted previously - up until the specified deadline, typically 24 hours after the quiz becomes available on the system. Once the students have submitted their answers by the specified time, the system will automatically form heterogeneous groups of 4 or 5 students each with each group containing students who chose different answers ${ }^{2}$.

The next time the student launches the app and logs in, she will be presented with the discussion space for her group. Each group will have its own "space" and the identities of the students in a

\footnotetext{
${ }^{2}$ If most students make the same choices, the system cannot form these groups. The instructor/TA will have to intervene and form the groups based on differences in the students' explanations. If the explanations are also more or less the same, that is an indication, if the common answer and explanation are correct, that the topic is simple and the instructor can simply move on to the next topic; or, if the common answer or explanation is wrong, that the topic is too difficult and calls for additional videos or other resources.
} 
group will not be known to the other students in the group. Instead, students will be named S1, S2, etc. Suppose a group has four students, S1 through S4. At the start of the discussion, the initial posts will be the answers submitted by each of S1 through $\mathrm{S} 4$ in response to the question in the quiz. As the discussion proceeds, each student will be expected to argue in favor of or against the ideas in the posts that have been made thus far. A student will have three distinct ways to react to a given post. The student could respond by creating a completely new post; the student could indicate that she supports the position expressed in the given post and provide an explanation why; or the student could indicate a conflict with the position in the given post and explain why.

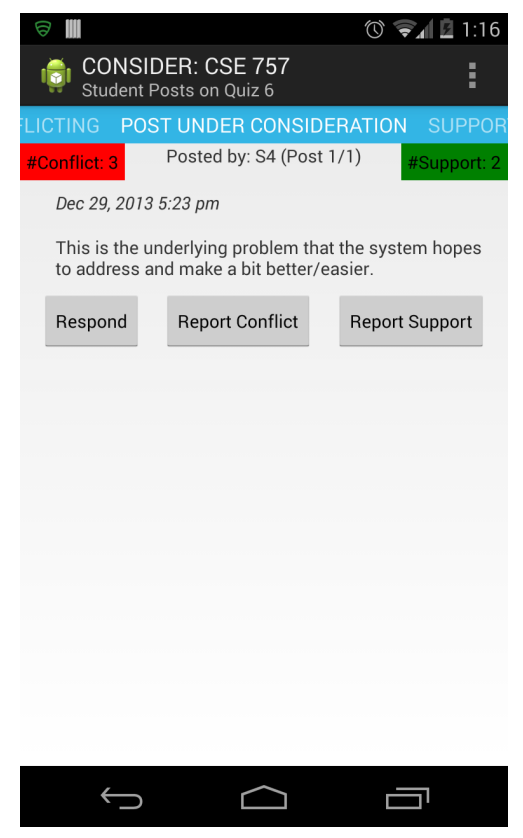

(a) Initial
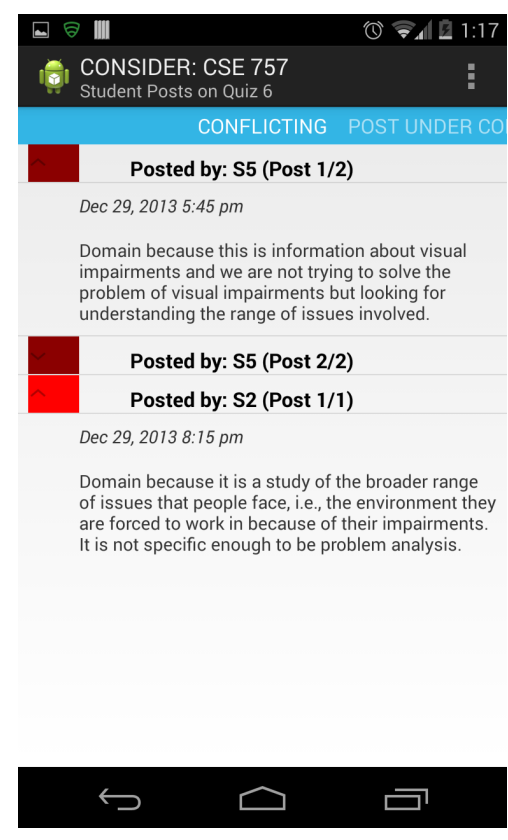

(b) Conflicting
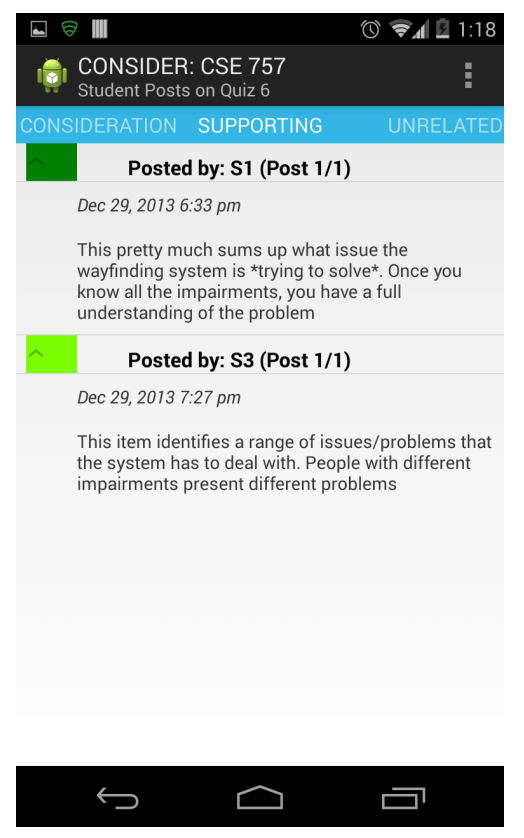

(c) Supporting

Figure 2: Initial, Conflicting, Supporting

Fig. 2 displays screens that may be seen during the discussion. Fig. 2(a) shows a post made by $\mathrm{S} 4$. The red block indicates that there are 3 posts that conflict with this post; i.e., since the time that S4 made this post, other students in the group have made three posts that conflict with the position of this post; the green block on the right similarly indicates that there are two posts that support it. Clicking on the "SUPPORTING", respectively, "CONFLICTING", tab on the top right/left (partially obscured) will bring up the supporting, respectively, conflicting, posts, seen in Figs. 2(b), 2(c). A student in the group can read any of these posts at any time. And can respond by creating a new post (which will bring up a screen that will allow the student to specify whether the new post is supporting or conflicting), or report conflict with another existing post, or report support with an existing post.

The students in the class will submit their original answers to the quiz approximately 4 days before the class meeting where the topic will be discussed. Once that submission deadline has passed, students will be able to see the discussion space of their respective groups. Each time the student 
launches the app, she will automatically see the posts of the group members and will be able to engage in the discussion with the group being expected to continue the discussion for about 48 hours. At the end of that period, the discussion space will no longer accept new posts but the students in the group will be able to read all the posts. At that point, each student will be required to individually submit a three part report consisting of: a summary of the starting positions of each student in the group; a summary of the discussion/debate in the group and any conclusions that were reached; the particular student's final answer (which may or may not be the same as the group's conclusion and may or may not be the same as that student's original answer). Each student will be required to submit her final report within 24 hours of the end of the discussion period; the screen for this is not shown. The quality of this report, including especially the summary of the discussion, will play the major role in determining the student's grade for the quiz. These reports, which the instructor will have available about 24 hours prior to the class meeting, will give the instructor detailed information about common misconceptions about the topic, how the students tried to resolve them, and what issues remained after the discussions.

\subsection{Testing and Refining the prototype}

We tested the prototype as follows. With the consent of the instructor of the software eng. course, one of the authors gave a presentation during a class meeting, explaining the notion of conflictdriven cooperative-learning and the approach of the CONSIDER system to enable such learning. We then asked for volunteers to test the prototype. Ten students volunteered. One of the other authors conducted a brief training session for the ten students, explaining how to download the app and use it. Two of the students did not have an Android device and we were able to lend them the devices. One student dropped out because of pressure of other work.

Following the initial submission which all students completed within 24 hours of starting, we divided them into two groups of four and five students respectively with each group consisting of students who chose different answers. This grouping was done by hand since the prototype did not include an implementation of the automatic formation of groups. We also sent students emails informing them that groups had been formed and asking them to start engaging in discussion with their group. The students had four days to complete the discussion. The students did not submit their final, individual reports (since by then the class was scheduled to have its midterm exam and students had to focus on that).

Overall, the students felt that the approach would indeed help them develop deep conceptual understanding of the problem provided the quiz were designed carefully. With respect to the prototype, they felt that the interface left much to be desired. For example, many of the screens were too crowded and it was difficult to navigate to specific posts. Our own observation, based on the posts that the students made, identified two key problems that threatened the entire approach. First, there was too little structure to the discussion so that once there had been a handful of posts, it was difficult for the students to keep track of how the discussion had evolved. Second, some students tended to make many more posts while others tended to make relatively few, in effect mirroring what typically happens in the classroom. 
Based on these results, we have redesigned the approach as follows. As before, all students in the class complete an on-line (conceptual) quiz that has a carefully designed multiple-choice component that will differentiate between students with different understandings of the topic and allow the system to organize students into heterogeneous groups of 4-5 students each. Also as before, the students will submit a brief textual explanation of their multiple-choice answer(s). The discussion in each group will be organized in a series of rounds which we will refer to as Round-0, Round-1, etc. The initial answers submitted by students in each group explaining their multiple choice answer will constitute the posts for Round-O of the discussion for that group. Once the groups have been formed, Round-1 of the discussion will begin. Each student in each group will be required to make exactly one post in this (and in each) round. Suppose a given group G has four students, S1, S2, S3, and S4. During Round-1, S1 will be able to see the posts made by all students in G during Round-0; S1 will not be able to see the posts made by the other students in Round-1 even if some of those other students have already made their posts for Round-1. In her post for Round-1, S1 will be required to pick whether she agrees with, disagrees with, or is neutral about the posts made by each of S1, S2, S3, and S4 in Round-0. This will be done not by writing text but by clicking on a green, red, or yellow button respectively that will be next to the posts from Round-0 of each of S1 through S4. If S1 clicks the red button for any of those posts, a textbox will open in which she will have to provide an explanation of why she disagrees with that post. She will also have the option of providing an explanation if she clicks the green or yellow button.

This means that each student is required to make exactly one post in each round and in doing so, she is required to consider the posts made by each of the students in the group in the previous round. In fact, S1 has to do this for her own post from Round-0. This is important because S1 may find the post of one or more of the other students from the previous round so compelling that she changes her mind and no longer agrees with what she said in the previous round. This is indeed the essence of CDCL and it will be highlighted by S1's clicking of the red button corresponding to her own post from the previous round. Each round will last 24 hours. S1 may work on her post for this round at any time during this period; and she can edit her post at any time during this period. No one else will see any part of S1's post during this period. At the end of the 24 hours, the round will finish, a new round will begin, and all students in the group will be able to see the posts that everyone in the group made during the just-ended round.

Figs. 3 and 4 displays the revised user interfaces. The quiz screen, Fig. 3, is as before except that the use of tabs provides more space to read the question and for the student to type in her answer. Fig. 4 shows the discussion screens. The first discussion screen shows Round-2 as indicated in the title. The arrows let the student navigate between the current round and earlier rounds (to read the posts from those rounds and return when she is done). The colored

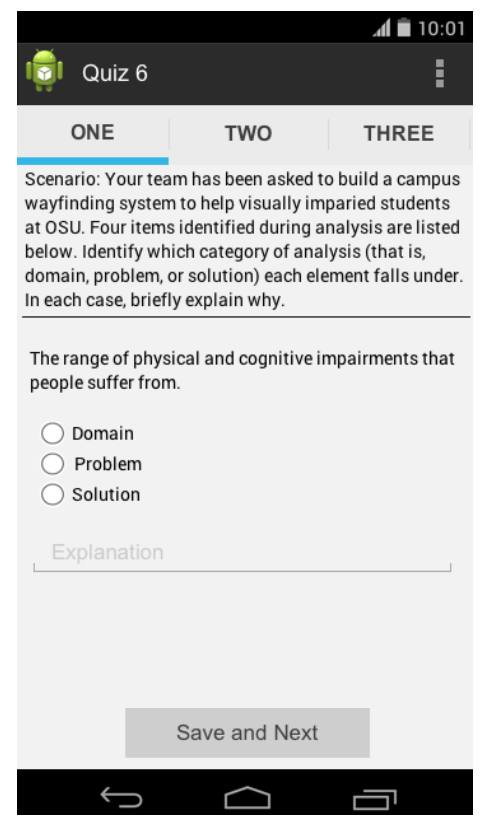

(a) Quiz

Figure 3: Revised UI 
buttons are the ones she clicks to indicate that her current positions conflicts with, agrees with, or is neutral about the post being displayed.

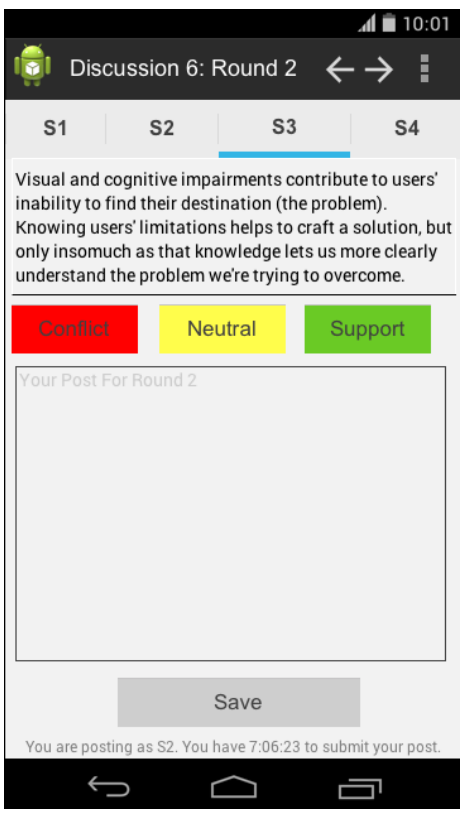

(a) Discussion

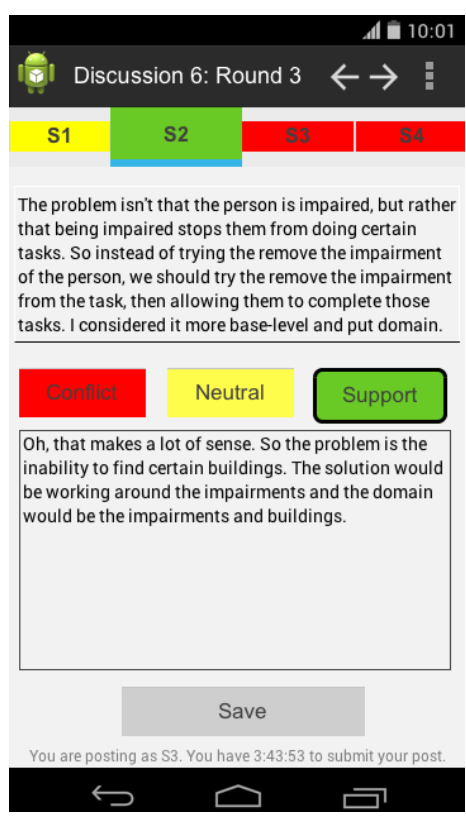

(b) Discussion-2

Figure 4: Revised UI (2)

\section{Conclusions}

Over the last several years, a number of approaches to cooperative learning have been developed including:

- Think-pair-share ${ }^{15}$ : Students think about a question or problem individually, possibly writing down their thoughts; then pair up with a peer and discuss each others' ideas; finally, the teacher solicits responses from the entire class.

- Jigsaw ${ }^{16}$ : Each student is in a home group and in an expert group. Each student in a home group is assigned a distinct topic. Students leave their home groups and join other students with the same assigned topic, forming the expert group on the topic. They explore their topic thoroughly and then return to their home groups; the student is then responsible for teaching his/her home group the particular topic. 
- Team-based learning (TBL $)^{17}$ : Students are organized into teams of five or six each. The course is organized into units, each two-three weeks long. Before the start of a unit, students are assigned readings. On the first day of the topic, students complete, as individuals, a short test on the topic. Immediately after, they take the same test as teams, coming to consensus on answers. The final step is a short lecture by the instructor focusing on common problems shared by many teams. The rest of the two-three week period is spent on activities that require the teams to apply the concepts and techniques to increasingly challenging problems.

Clearly, there are important differences between these approaches and CDCL. One advantage of the approaches such as Jigsaw and TBL is that they allow students to develop social and team-working skills. By contrast, the focus of CDCL and, in particular, of CONSIDER, is on helping students develop deep understanding based on cognitive conflict with peers. Moreover, by exploiting the specific affordances of online and mobile technologies, the CONSIDER approach addresses many of the problems that in-class CDCL approaches such as peer instruction ${ }^{14}$ encounter including: a) Ensuring effective and equal participation by all members in a group;

b) Ensuring students have adequate time to understand the positions of their peers, compare them to their own, and formulate appropriate responses;

c) Making it possible for the individual student to review the discussion that her group members went through in arriving at their final positions and the evolution of her own thinking as the discussion progressed, possibly in preparation for the final exam in the course; and

d) Allowing the instructor to assess how effective the initial multiple-choice question was in enabling the formation of heterogeneous groups as well as how effective the discussions in the groups were in helping students develop deep understanding of the underlying concepts by looking at the summaries of the discussions submitted by the various students in the class.

We conclude with a mention of our plans for future work. We are currently implementing the revised version of the CONSIDER tool. Once it is complete, we plan to test it in a junior-level course on programming language concepts. This course, unlike our software engineering course, is not a flipped course. While our original work on CONSIDER started as a tool to address the problems we saw in flipped courses, there is, in fact, no reason why it cannot be used in traditional courses. On the other end of the spectrum, it may also be applicable to MOOCs. One of the major difficulties with MOOCs is, of course, that students do not get to interact with the instructor unlike in regular courses. But we may be able to compensate for this by organizing students in the MOOC into topic-specific groups, ensuring heterogeneity of the groups with respect to their understanding of the topic, and use the CONSIDER approach to enable students to learn from their peers! If this succeeds, it could dramatically alter the potential of MOOCs.

\section{References}

[1] J Piaget. The early growth of logic in the child. Routledge and Kegan Paul, 1964.

[2] O Olivares. Collaborative critical thinking. Issues in Educational Research, 15(1):86-100, 2005. 
[3] R Felder and R Brent. Effective strategies for cooperative learning. Journal of Cooperation and Collaboration in College Teaching, 10:69-75, 2001.

[4] D Johnson, R Johnson, and K Smith. Active learning: Cooperation in the college classroom. Interaction Book, 1998.

[5] B Millis and P Cottell. Cooperative Learning for Higher Education Faculty. American Council on Education, 1998.

[6] M Lage, G Platt, and M Treglia. Inverting the classroom: A gateway to creating an inclusive learning environment. Journal of Economic Education, 31(1):30-43, 2000.

[7] J Foertsch, G Moses, J Strikwerda, and M Litzkow. Reversing the Lecture/Homework Paradigm Using eTEACH Web-based Streaming Video Software. Journal of Engineering Education, 91(3):267-274, 2002.

[8] J Thomas and T Philpot. An inverted teaching model for a mechanics of materials course. In Proc. of ASEE Annual Conf., pages 1-25. ASEE, 2012.

[9] W Redekopp and G Ragusa. Evaluating flipped classroom strategies and tools for computer engineering, Paper ID \#7063. In Proc. of ASEE Annual Conf., pages 1-18. ASEE, 2013.

[10] B Swartz, S Velegol, and J Laman. Three approaches to flipping CE courses: Faculty perspectives and suggestions, paper id \#7982. In Proc. of ASEE Annual Conf., pages 1-18. ASEE, 2013.

[11] E Gehringer and B Peddycord. The inverted lecture model: A case study in computer architecture. In Proc. of SIGCSE, pages 489-494. ACM, 2013.

[12] W Doise and G Mugny. The social development of the intellect. Oxford: Pergamon, 1984.

[13] C Howe and A Tolmie. Productive interaction in the context of computer-supported collaborative learning in science. In Learning with computers, pages 24-46. Routledge, 1999.

[14] C Crouch and E Mazur. Peer instruction: Ten years of experience and results. American Journal of Physics, 69(9):970-977, 2001.

[15] F Lyman. The responsive classroom discussion: The inclusion of all students. In A Anderson, editor, Mainstreaming Digest, pages 109-113. Univ. of Maryland Press, 1981.

[16] E Aronson, N Blaney, C Stephen, J Sikes, and M Snapp. The jigsaw classroom. Sage Co., 1978.

[17] L Michaelsen and M Sweet. The essential elements of team based learning. In New directions for teaching and learning, No. 116, pages 7-27. Wiley InterScience, 2008. 